\title{
State-of-the-art automated patch clamp devices: heat activation, action potentials, and high throughput in ion channel screening
}

\section{Sonja Stoelzle ${ }^{1}$, Alison Obergrussberger ${ }^{1}$, Andrea Brüggemann ${ }^{1}$, Claudia Haarmann ${ }^{1}$, Michael George ${ }^{1}$, Ralf Kettenhofen ${ }^{2}$ and Niels Fertig ${ }^{1}$}

${ }^{1}$ Nanion Technologies GmbH, Munich, Germany

${ }^{2}$ Axiogenesis AG, Cologne, Germany

\section{Edited by:}

Juha Kammonen, Pfizer, UK

Reviewed by:

Christian Wahl-Schott,

Ludwig-Maximilian University,

Germany

Michel Vivaudou, Institut de Biologie

Structurale, France

Lishuang Cao, Pfizer, UK

*Correspondence:

Sonja Stoelzle, Nanion Technologies GmbH, Gabrielenstrasse 9, 80636

Munich, Germany.

e-mail:sonja@nanion.de
Ion channels are essential in a wide range of cellular functions and their malfunction underlies many disease states making them important targets in drug discovery. The availability of standardized cell lines expressing ion channels of interest lead to the development of diverse automated patch clamp (APC) systems with high-throughput capabilities. These systems are now available for drug screening, but there are limitations in the application range. However, further development of existing devices and introduction of new systems widen the range of possible experiments and increase throughput. The addition of well controlled and fast solution exchange, temperature control and the availability of the current clamp mode are required to analyze standard cell lines and excitable cells such as stem cell-derived cardiomyocytes in a more physiologically relevant environment. Here we describe two systems with different areas of applications that meet the needs of drug discovery researchers and basic researchers alike. The here utilized medium throughput APC device is a planar patch clamp system capable of recording up to eight cells simultaneously. Features such as temperature control and recordings in the current clamp mode are described here. Standard cell lines and excitable cells such as stem cell-derived cardiomyocytes have been used in the voltage clamp and current clamp modes with the view to finding new drug candidates and safety testing methods in a more physiologically relevant environment. The high-throughput system used here is a planar patch clamp screening platform capable of recording from 96 cells in parallel and offers a throughput of 5000 data points per day. Full dose response curves can be acquired from individual cells reducing the cost per data point. The data provided reveals the suitability and relevance of both APC platforms for drug discovery, ion channel research, and safety testing.

Keywords: automated patch clamp, electrophysiology, temperature control, TRPV3, hERG, nAChR, current clamp, ion channels

\section{INTRODUCTION}

Ion channels are pore-forming proteins that catalyze the passive transport of ions through biological membranes. Given the importance of ion channels in many physiological processes, it is no surprise that they are a major therapeutic target (Hille, 1992; Ashcroft, 2000). To date over 13\% of currently known drugs have been shown to act primarily on ion channels, a multi-billion dollar industry (Clare, 2010).

Patch clamp electrophysiology remains the gold standard for studying ion channels since it was first described in the 1970s (Neher and Sakmann, 1976). However, conventional patch clamp is notoriously low throughput and technically demanding. Thus, automation of the patch clamp technique increases throughput and ease of use (Farre et al., 2009), bringing patch clamp to a wider audience.

Over the last decade, several automated patch clamp (APC) devices became available and are now commonplace in many laboratories (for recent reviews see Dunlop et al., 2008; Farre et al.,
2008). These devices provide information rich data whilst increasing throughput, which is essential for both drug discovery and safety testing. Such APC devices are not limited to the pharmaceutical industry. Universities and research institutions have also started to implement the use of higher throughput APC devices in their laboratories (Milligan et al., 2009; Balansa et al., 2010). National screening centers and high-throughput core facilities are appearing worldwide, combining increased throughput, sophistication, and high quality.

However, the providers of APC devices are pushing the boundaries by continually improving existing platforms and creating new and innovative devices, which have higher throughput and new features. Such features are introduced in this paper.

\section{MATERIALS AND METHODS SYSTEM COMPONENTS}

The medium throughput patch clamp device used here was a Patchliner System (Nanion Technologies, Germany). It includes 
four (Patchliner Quattro) or eight (Patchliner Octo) amplifier channels (EPC-10 Quadro amplifiers, HEKA Elektronik, Germany), PatchControlHT software, integrated with PatchMaster (HEKA Elektronik, Germany), for acquisition of data, and online analysis of the recorded data. The data analysis software for visualization of traces and results of data analysis is IGOR Pro-based (WaveMetrics, USA). The data output and compound information is compatible with most database formats. A graphical user interface is used to program and execute up to 48 unattended recordings, approximately 500 data points per day can be generated. User intervention is possible at any time during an experiment. The software offers a detailed user control in combination with versatile experimental possibilities. In comparison to other available APC devices the Patchliner is equipped with temperature control, continuous waste removal allowing an unlimited number of compound additions, and the ability to perform current clamp recordings.

The high-throughput system utilized here was the SyncroPatch 96 (Nanion Technologies, Germany), a screening platform capable of recording from 96 cells in parallel. Full dose response curves can be acquired from individual cells with giga-ohm (G $\Omega$ ) seals, generation of up 5000 data points per day is possible. The platform has built-in amplifiers (Triton+, Tecella LLC, USA), its own dedicated software (PatchControl96, Nanion Technologies, Germany), and a data analysis package. Temperature control or current clamp are not integrated features. Data output and compound information is compatible with most database formats.

For both systems, planar borosilicate-glass patch clamp chips are used (Farre et al., 2009).

\section{CELL CULTURE FOR PLANAR PATCH CLAMP}

For planar patch clamp, a wide range of different cell suspensions can be used (Bruggemann et al., 2008; Li et al., 2008; Milligan et al., 2009). Cell suspensions for APC devices utilizing planar patch clamp chips should be homogeneous (Milligan et al., 2009), since the cell capture is blind. The cells are ideally single. Cell clusters, cell fragments, or debris in the suspension decrease the cell capture rate and, thus, the overall success rate.

\section{Standard cell lines}

The confluency of the cells should be in the range of 50-80\%. For culturing cells for use on the Patchliner and SyncroPatch 96, T75 flasks are typically used. For harvesting the cells for patch clamp experiments, no significant difference in percentage of giga-ohm seals could be found for using Trypsin, accutase, or phosphatebuffered saline ethylenediaminetetraacetic acid (PBS-EDTA) for lifting the cells.

Cell lines used in this paper:

hERG stably expressed in HEK cells (Millipore, USA). hTRPV3 stably expressed in HEK cells (Millipore, USA). $\mathrm{hNa}_{\mathrm{v}} 1.5$ stably expressed in HEK cells (Millipore, USA). $\mathrm{P}_{2} \mathrm{X}_{2 / 3}$ receptors stably expressed in $1321 \mathrm{~N} 1$ cells (Evotec, Germany).

HEK cells stably expressing homomeric human nAChR $\alpha 7$ subunits (Galantos Pharma GmbH, Germany).
$\mathrm{GABA}_{\mathrm{A}}$ subunits $\alpha 1 \beta 2 \gamma 2$ stably expressed in HEK cells (source anonymous).

Harvesting protocol for cell lines. Amounts are listed for a T75 flask exemplarily:

- Wash twice with $10 \mathrm{ml}$ PBS (without $\mathrm{Ca}^{2+}$ and $\mathrm{Mg}^{2+}$ ).

- Add $2 \mathrm{ml}$ of detacher (PBS-EDTA 2 mM, Trypsin/EDTA, Accutase etc.).

- Incubate approximately $3 \mathrm{~min}$ in a humidified incubator at $37^{\circ} \mathrm{C}$ and $95 \% \mathrm{O}_{2} / 5 \% \mathrm{CO}_{2}$.

- Check the detachment of cells using a microscope. Move the plate or flask gently to detach all cells from the bottom (do not hit the flask, tap gently if necessary).

- Add $10 \mathrm{ml}$ of cell culture medium (room temperature, RT), according to the cells used.

- Pipette the cells gently up and down with a 10-ml pipette.

- After pipetting five times, look at the cells under a microscope. If the cells are single ( 80-90\%), no further pipetting is needed.

- If cells still form clusters, gently pipette cells another 10 times. Repeat this step until cells are single ( 80-90\%).

- Centrifuge the cells (2 min, $100 \mathrm{~g}$ ).

- Discard the supernatant.

- Resuspend the cells in external recording solution resulting in a cell density of approximately $1 \times 10^{6}$ cells $/ \mathrm{ml}$.

- A visual control of the cell suspension under the microscope should reveal single, round cells with smooth membrane edges and few cell clusters.

- Transfer cells to the cell hotel of the Patchliner where cells are continuously pipetted up and down to maintain single cells and viability.

\section{Stem cell-derived cardiomyocytes}

Differentiation of genetically modified mouse embryonic stem cells (mESC) and the antibiotic selection of the mESC-derived cardiomyocytes have been described previously in detail (Kolossov et al., 2006).

Vials of at least one or five million viable mESC-derived cardiomyocytes (Cor.At cells, Lonza, Walkersville, USA, catalog numbers XCAC-1010 or XCAC-1050, respectively) obtained directly from the manufacturer (Axiogenesis, Cologne, Germany) were thawed as described in the distributors technical manual (https://www.lonza.com/go/literature/). For long-term storage, the cells are frozen as single cell suspensions in liquid nitrogen or $-150^{\circ} \mathrm{C}$ freezers. When cultured overnight at an appropriate cell density, the thawed cardiomyocytes form spontaneously and synchronously contracting monolayers.

Cells were seeded at a density of $10^{5}$ viable cells $/ \mathrm{cm}^{2}$ culture area in one T25 cell culture flask with $5 \mathrm{ml}$ Cor.At Complete Culture Medium when a vial with one million viable mESCderived cardiomyocytes was used. Two T75 cell culture flasks each with $10 \mathrm{ml}$ Cor.At Complete Culture Medium were used when a vial containing five million mESC-derived cardiomyocytes was taken.

iCell cardiomyocytes (Cellular Dynamics International, Madison, WI, USA) were plated on T25 culture flasks coated with $0.1 \%$ gelatin as per manufacturers' instructions. A vial 
containing $>1.5 \times 10^{6}$ platable cells (catalog number CMC-100110-001) was plated on one T25 flask, a vial containing $>7.5 \times 10^{6}$ platable cells (catalog number CMC-100-110-005) was plated on five T25 flasks. For each $1 \times 10^{6}$ viable cells, $9 \mathrm{ml}$ cold iCell Cardiomyocytes Plating Media $\left(4^{\circ} \mathrm{C}\right)$ was used. After $24 \mathrm{~h}$ the media was exchanged for iCell Cardiomyocytes Maintenance Media.

Harvesting protocol for mouse stem cell-derived Cor.At cardiomyocytes. Amounts are listed for a T75 flask exemplarily:

- Cells must be cultured for at least 2-4 days before patch clamp experiments are performed.

- Wash twice with $10 \mathrm{ml} 4^{\circ} \mathrm{C}$ cold PBS (without $\mathrm{Ca}^{2+} / \mathrm{Mg}^{2+}$ )/EDTA (2 mM).

- Incubate at $4^{\circ} \mathrm{C}$ for $15 \mathrm{~min}$.

- Remove PBS/EDTA.

- Add 5 ml pre-warmed (RT) Trypsin 0.05\%/EDTA 0.02\% in PBS solution.

- Incubate $4-5 \mathrm{~min}$ in a humidified incubator at $37^{\circ} \mathrm{C}$ and $95 \%$ $\mathrm{O}_{2} / 5 \% \mathrm{CO}_{2}$.

- Check the detachment of cells under a microscope. Move the plate or flask gently to detach all cells from the bottom (do not hit the flask).

- Add $10 \mathrm{ml}$ of Cor.At Complete Culture Medium (RT).

- Centrifuge the cells (2 min, $100 \mathrm{~g}$ ).

- Discard the supernatant.

- Add external recording solution resulting in a cell density of approximately $1 \times 10^{6}-5 \times 10^{7} / \mathrm{ml}$. Carefully resuspend the cells by gentle pipetting (two times max.).

- A visual control of the cell suspension under the microscope should reveal single, round cells with smooth membrane edges and no cell clusters.

- Transfer cells to the cell hotel of the Patchliner where cells are continuously pipetted up and down to maintain single cells and viability.

Harvesting protocol for human iPS cell-derived iCell cardiomyocytes. Amounts are listed for a T25 flask exemplarily:

- Cells should be cultured for at least 2-4 days before patch clamp experiments are performed.

- Wash twice with $5 \mathrm{ml} 4^{\circ} \mathrm{C}$ cold PBS (without $\mathrm{Ca}^{2+} / \mathrm{Mg}^{2+}$ )/EDTA $(2 \mathrm{mM})$.

- Add $5 \mathrm{ml} 4^{\circ} \mathrm{C}$ cold PBS (without $\mathrm{Ca}^{2+} / \mathrm{Mg}^{2+}$ )/EDTA (2 mM).

- Incubate at $4^{\circ} \mathrm{C}$ for $15 \mathrm{~min}$.

- Remove PBS/EDTA.

- Add 2 ml Trypsin 0.05\%/EDTA 0.02\% in PBS solution.

- Rock the dish from side to side to ensure an even distribution of Trypsin.

- Immediately remove the Trypsin (before cells start to detach). Despite removing the liquid, there is still enough Trypsin on the surface to detach the cells.

- Incubate the flask for $3-8 \mathrm{~min}$ at $37^{\circ} \mathrm{C}$ and $95 \% \mathrm{O}_{2} / 5 \% \mathrm{CO}_{2}$. Check the detachment of cells under a microscope after $3 \mathrm{~min}$. Move the plate or flask gently to detach all cells from the bottom (do not hit the flask, tap gently if required). If cells are not detached return the flask to the incubator.
- Once cells start to detach, add $1 \mathrm{ml}$ media and $1 \mathrm{ml}$ external recording solution. Carefully resuspend the cells by gentle pipetting (two times max.).

- Transfer cells to the cell hotel of the Patchliner where cells are continuously pipetted up and down to maintain single cells and viability.

Patch clamp solutions. Internal solution: $50 \mathrm{mM} \mathrm{KCl}, 10 \mathrm{mM}$ $\mathrm{NaCl}, 60 \mathrm{mM}$ KF, $20 \mathrm{mM}$ EGTA, $10 \mathrm{mM}$ HEPES/KOH, pH 7.2 (for Figures 1, 2, 5, 6, and 8 ) or $50 \mathrm{mM} \mathrm{CsCl}, 10 \mathrm{mM} \mathrm{NaCl}, 60 \mathrm{mM}$

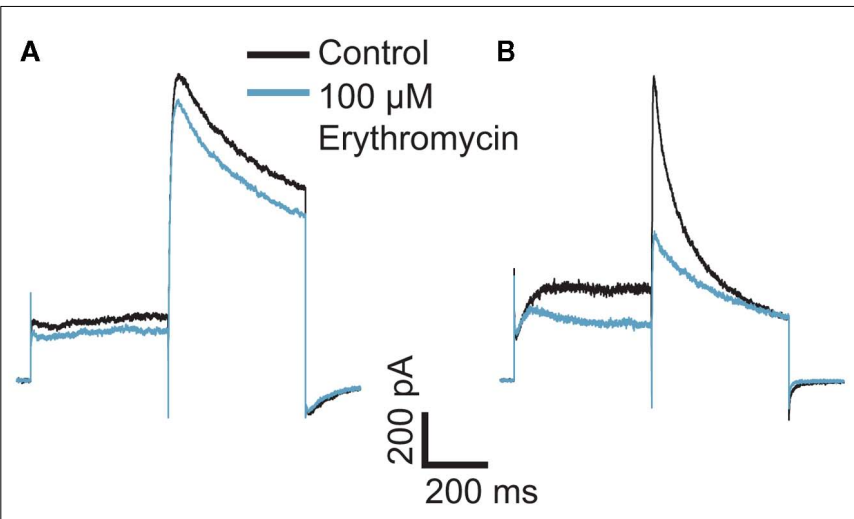

FIGURE 1 | Effect of erythromycin on hERG-mediated currents at (A) room temperature and $(\mathbf{B}) 3^{\circ} \mathbf{C}$. The graphs are shown on the same scale. Hundred micromolar erythromycin significantly blocked hERG currents at $35^{\circ} \mathrm{C}$ but had little effect on hERG currents at RT, $n=1$ each.

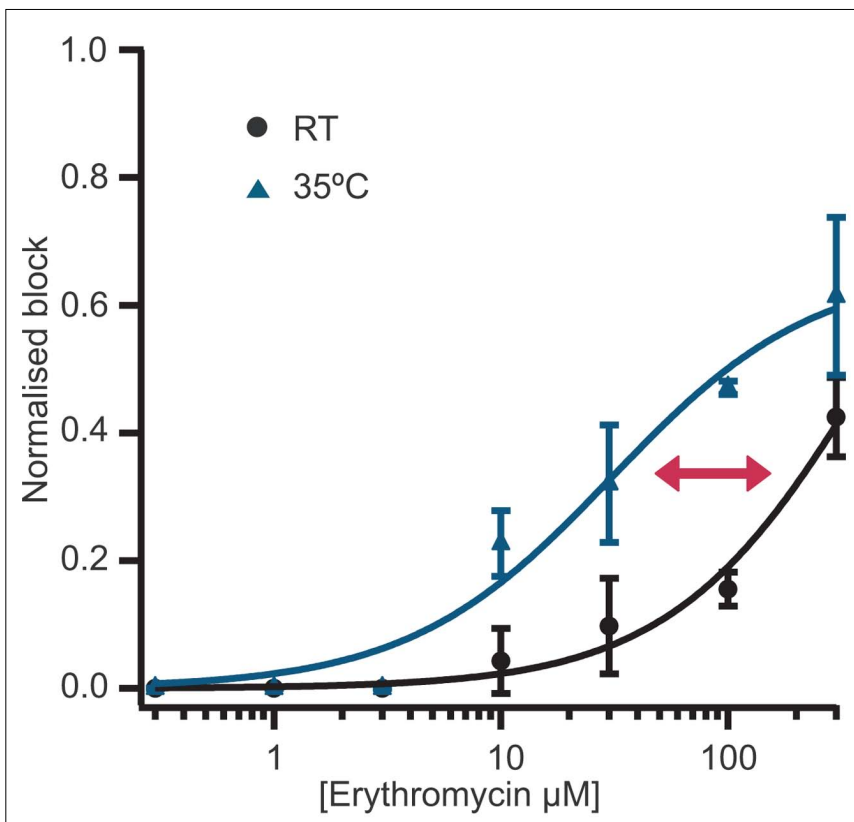

FIGURE 2 | Concentration response curves for erythromycin at room temperature $(n=12)$ and at $35^{\circ} \mathrm{C}(n=18)$. Erythromycin is approximately 10-fold more potent at $35^{\circ} \mathrm{C}$ compared with room temperature. An overlay of the concentration response curves at room temperature and $35^{\circ} \mathrm{C}$ clearly shows the shift in potency. 


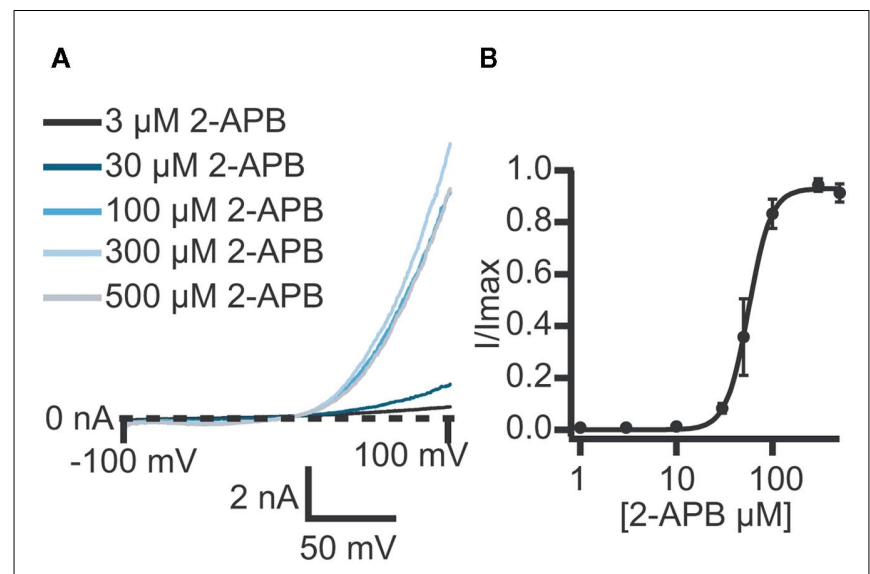

FIGURE 3 | (A) Currents elicited using a voltage ramp protocol from -100 to $100 \mathrm{mV}$ over $200 \mathrm{~ms}$ and activation of TRPV3 receptors by increasing concentrations of 2-APB. (B) Concentration response curve for $n=11$ cells revealing an $\mathrm{EC}_{50}$ for 2 -APB of $61.1 \pm 7.6 \mu \mathrm{M}$.

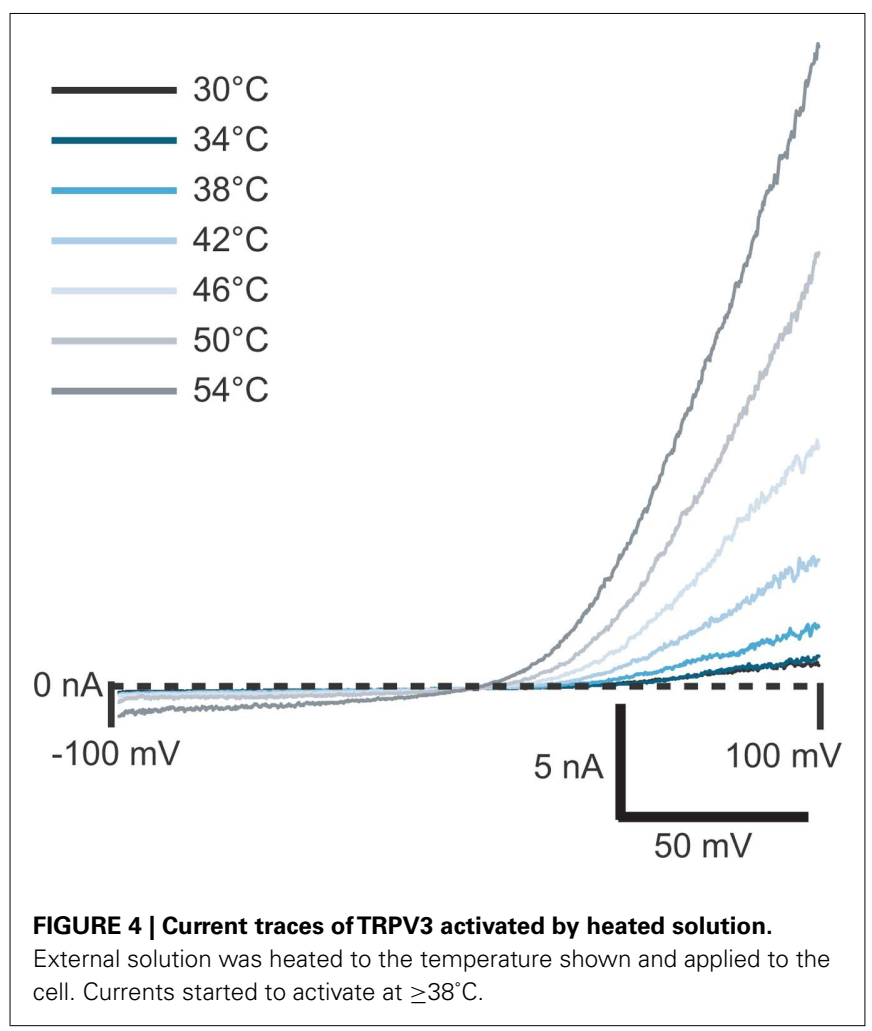

CsF, 20 mM EGTA, 10 mM HEPES/CsOH (for Figures 3, 4, 9, and 10). External solution (except for recordings shown in Figure 9B): $140 \mathrm{mM} \mathrm{NaCl}, 4 \mathrm{mM} \mathrm{KCl}, 1 \mathrm{mM} \mathrm{MgCl} 2,2 \mathrm{mM} \mathrm{CaCl}_{2}, 5 \mathrm{mM} \mathrm{D-}$ Glucose monohydrate, $10 \mathrm{mM}$ HEPES/NaOH pH 7.4. External solution for nicotinic $\alpha 7$ channel recordings (Figure 9B): $80 \mathrm{mM}$ $\mathrm{NaCl}, 3 \mathrm{mM} \mathrm{KCl}, 45 \mathrm{mM} \mathrm{CaCl}_{2}, 10 \mathrm{mM}$ HEPES $\left(\mathrm{Na}^{+}\right.$salt $) / \mathrm{HCl}$, $\mathrm{pH}$ 7.4. Solutions for action potential (AP) recording in the conventional patch clamp rig (Figure 5G) were $130 \mathrm{mM}$ KAs, $15 \mathrm{mM}$ $\mathrm{KCl}, 5.5 \mathrm{mM} \mathrm{MgCl}_{2}, 5 \mathrm{mM} \mathrm{Na} 2 \mathrm{ATP}, 5 \mathrm{mM} \mathrm{K}$ phosphocreatine,
$10 \mathrm{mM}$ HEPES, pH 7.25 (internal) and $140 \mathrm{mM} \mathrm{NaCl}, 4 \mathrm{mM} \mathrm{KCl}$, $2 \mathrm{mM} \mathrm{CaCl}_{2}, 1 \mathrm{mM} \mathrm{MgCl}_{2}, 10 \mathrm{mM}$ glucose, $10 \mathrm{mM}$ HEPES, $\mathrm{pH}$ 7.35 (external).

Electrophysiology. Whole cell patch clamp recordings were conducted as previously described (Farre et al., 2009; Stoelzle et al., 2011). Currents were elicited using voltage protocols in the voltage clamp mode. For hERG, a voltage step protocol from the holding potential $(-80 \mathrm{mV})$ to $+40 \mathrm{mV}$ for $500 \mathrm{~ms}$ followed by a $500-\mathrm{ms}$ step to $-40 \mathrm{mV}$, repeated every $20 \mathrm{~s}$. Peak amplitude at $-40 \mathrm{mV}$ was used for analysis. For $\mathrm{Na}_{\mathrm{v}}$ 1.5, currents were elicited using $10 \mathrm{~ms}$ voltage steps from -120 to $0 \mathrm{mV}$ repeated every $1 \mathrm{~s}$. For ligand-gated experiments, cells were held at a constant holding potential of $-80 \mathrm{mV}$ and solutions were exchanged within $100 \mathrm{~ms}$ to activate receptors and minimize ligand exposure time. For heat activation of TRPV3 channels, external solution was heated to the temperature indicated and applied to the cell. Alternatively, 2-APB at increasing concentrations at RT was used to activate TRPV3. A voltage ramp protocol from - 100 to $100 \mathrm{mV}$ over $200 \mathrm{~ms}$ was used to record TRPV3 currents. Current amplitude at $90 \mathrm{mV}$ was used for analysis. APs were generated using a depolarizing pulse to the threshold at which an AP was elicited. Membrane potential was kept at -80 to $-100 \mathrm{mV}$ (cell dependent). The AP traces shown represent an average response of four recorded APs. The APs were normalized to the time point of the beginning of the upstroke. Equipment: NPC-16 Patchliner Octo (with temperature control option) and SyncroPatch 96 (Nanion Technologies GmbH, Germany). Patch clamp amplifier for the Patchliner: EPC-10 Quadro (HEKA Elektronik GmbH, Germany), patch clamp amplifier for the SyncroPatch 96: Triton + (Tecella, CA, USA), PatchControl HT and PatchControl 96 software (Nanion Technologies GmbH, Germany). Software for data acquisition (PatchMaster, HEKA Elektronik GmbH, Germany; PatchControl 96, Nanion Technologies $\mathrm{GmbH}$, Germany) and analysis (IGOR Pro WaveMetrics Inc., OR, USA and SyncroPatch Data Analysis Package, Nanion Technologies GmbH, Germany). NPC-16 or NPC-96 chips (single-use, disposable; Nanion Technologies GmbH, Germany) were used.

\section{APPLICATIONS AND NOVEL FEATURES TEMPERATURE REGULATION \\ Experiments at physiological temperature}

Compounds can display different properties or different potencies at physiological temperature $\left(35^{\circ} \mathrm{C}\right)$ vs. RT. Therefore, it is a desirable option to be able to study ion channels at elevated temperature. To meet this need, several heating elements were introduced into the Patchliner. The surrounding of the planar patch clamp chip can be heated to maintain constant, physiological temperature. The solution, which is pipetted onto the cell, can also be heated separately. To prevent any degradation of compounds inside the pipette due to long heating phases, only the volume which is required (typically $40-100 \mu \mathrm{l}$, depending on the application) is heated, directly before application to the chamber of the patch clamp chip. Heating of the solution, which is applied to the cell takes $23.4 \pm 4 \mathrm{~s}$ (for temperatures between 30 and $70^{\circ} \mathrm{C}$; data not shown).

One compound, which has been shown to have an increase in potency at physiological temperature, is erythromycin. 

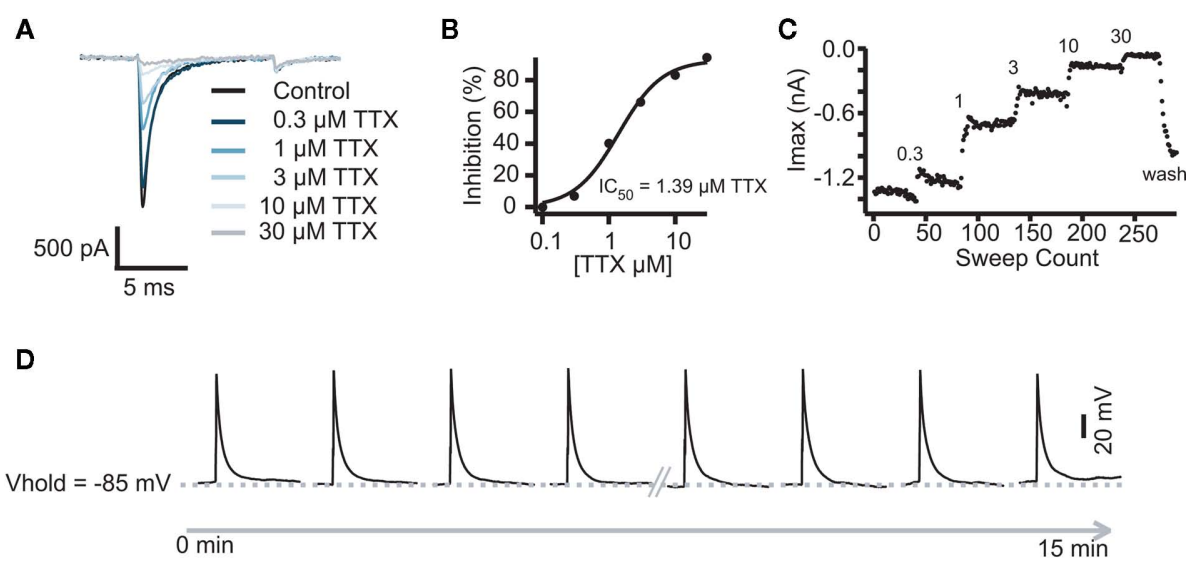

E

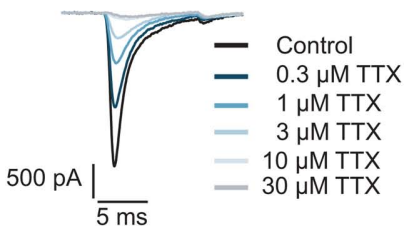

$\mathrm{F}$

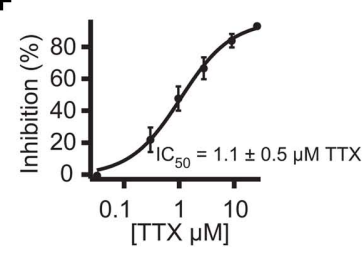

G

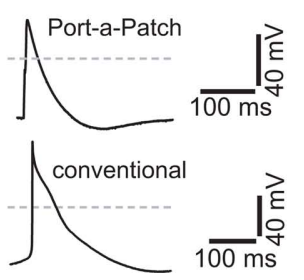

FIGURE 5 | (A) Representative traces of a Cor.At cardiomyocyte recorded in the voltage clamp mode and block by increasing concentrations of TTX. Raw data of $\mathrm{Na}^{+}$currents in control solution and in the presence of increasing TTX concentrations $(0.3,1,3,10$, and $30 \mu \mathrm{M})$, elicited by $10 \mathrm{~ms}$ voltage steps to $0 \mathrm{mV}$ from a holding potential of $-80 \mathrm{mV}$, sweep interval $2 \mathrm{~s}$. (B) Corresponding concentration response curve with a calculated $I C_{50}$ of $1.3 \pm 0.4 \mu \mathrm{M}(n=3)$. (C) Corresponding time plot of the experiment showing the stability of the recording. Current amplitude was reduced step by step upon application of the increasing concentrations. A washout of TTX was performed at the end of experiment. (D) Representative traces of highly reproducible APs as recorded in the current clamp mode. Sweep interval between each stimulus was $10 \mathrm{~s}$. Traces were recorded over $15 \mathrm{~min}$, the first and the last 4 APs are shown. The same experiment as shown in (A) was performed on the semi-automated patch clamp system Port-a-Patch (E). The corresponding $I_{50}$ was calculated to be $1.1 \pm 0.5 \mu \mathrm{M}$ $(n=4)$ (F). (G) Comparison of an AP recorded with the Port-a-Patch (top trace) and using a conventional patch clamp rig (lower trace). Gray line indicates $0 \mathrm{mV}$.
Erythromycin is a macrolide antibiotic, which can cause QT prolongation and cardiac arrhythmia. Erythromycin has been shown to block hERG channels at physiological temperature with an $\mathrm{IC}_{50}$ of approximately $40 \mu \mathrm{M}$ (Stanat et al., 2003). However, at RT erythromycin is much less potent. At a concentration of $100 \mu \mathrm{M}$, erythromycin causes no significant block of hERG currents at RT but significantly blocks currents at physiological temperature (Guo et al., 2005).

Here we present data collected on a Patchliner Octo with temperature control at RT and at $35^{\circ} \mathrm{C}$ and the effect this has on the potency of erythromycin. Current responses of two individual cells to $500 \mathrm{~ms}$ voltage pulses to $+40 \mathrm{mV}$ and then $-40 \mathrm{mV}$ in the presence and absence of $100 \mu \mathrm{M}$ erythromycin at RT and $35^{\circ} \mathrm{C}$ are shown in Figure 1. At RT (Figure 1A) $100 \mu \mathrm{M}$ erythromycin caused little reduction in current amplitude (at $-40 \mathrm{mV}$; approx. $15 \%$ ) compared with an almost 50\% reduction in current amplitude at $35^{\circ} \mathrm{C}$ (Figure 1B). This is in good agreement with the literature (Guo et al., 2005).

Typically, single concentrations of erythromycin were applied to each cell. Figure 2 shows averaged concentration response curves for erythromycin at RT and at $35^{\circ} \mathrm{C}$ overlaid. At higher concentrations $(300 \mu \mathrm{M})$, erythromycin did block hERG currents at RT by approximately $40 \%$ and gave an $\mathrm{IC}_{50}$ of $427.5 \mu \mathrm{M}$ calculated from the graph $(n=12)$. At $300 \mu \mathrm{M}$, erythromycin blocked
hERG currents at $35^{\circ} \mathrm{C}$ by $70 \%$ and the $\mathrm{IC}_{50}$ at this temperature was calculated to be $30.7 \mu \mathrm{M}(n=18)$. This is in excellent agreement with values reported in the literature (Stanat et al., 2003).

Table 1 shows success rates of reaching a giga-ohm seal and cell parameters for hERG stably expressed in HEK cells (Millipore, USA), $n=35$.

\section{Heat activation of TRPV3}

Transient receptor potential (TRP) channels are an important class of receptors found widely distributed throughout the mammalian central and peripheral nervous systems. They have been shown to be activated by many stimuli including temperature, mechanostimulation, divalent cations, and $\mathrm{pH}$ (for review see Clapham, 2003). TRP channels are receiving much attention as potential targets for the treatment of, for example, chronic pain, asthma, and diabetes insipidus (Clapham, 2003; Gudermann and Flockerzi, 2005).

We have used the Patchliner to study TRPV3 channels using either 2-APB or heat to activate the receptors. High quality data could be achieved with a high success rate for obtaining seals in the G $\Omega$ range ( $>80 \%$ ). Table 2 shows success rates and cell parameters for TRPV3 stably expressed in HEK cells (Millipore, USA) activated by either 2-APB or heat. 


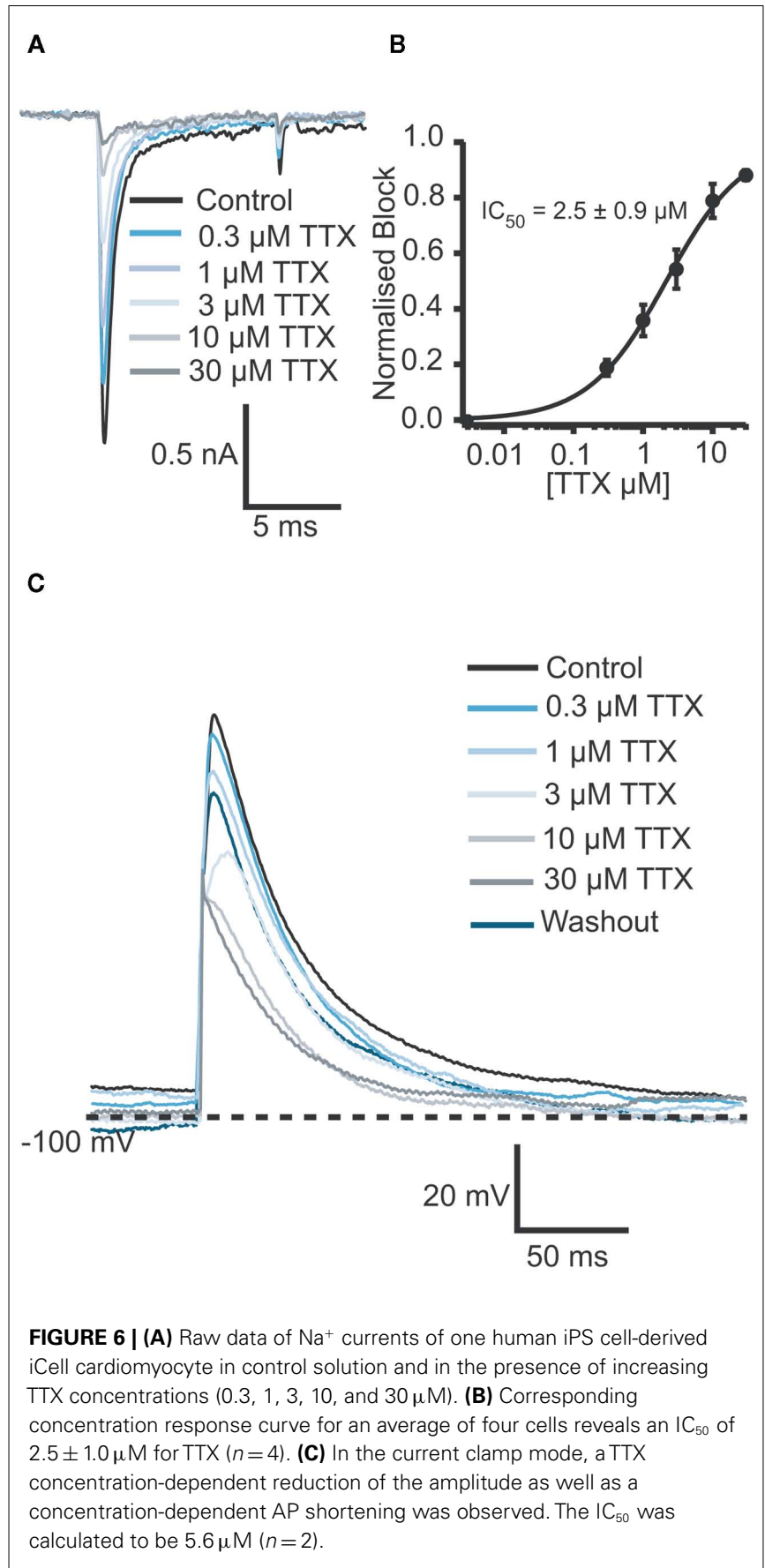

TRPV3 currents were activated by 2 -APB in a concentrationdependent manner. Figure 3 shows current traces of TRPV3 expressed in HEK cells and activation by 2-APB. The concentration response curve is also shown revealing an $\mathrm{EC}_{50}=61.1 \pm 7.6 \mu \mathrm{M}$ $(n=11)$. This is in good agreement with values reported in the literature (Chung et al., 2004; Hu et al., 2009).

TRPV 3 receptors can also be activated by temperature. Figure 4 shows the activation of TRPV3 channels by increasing temperature. To do these experiments, external bath solution was heated in the robotic pipette and after the set temperature was reached,

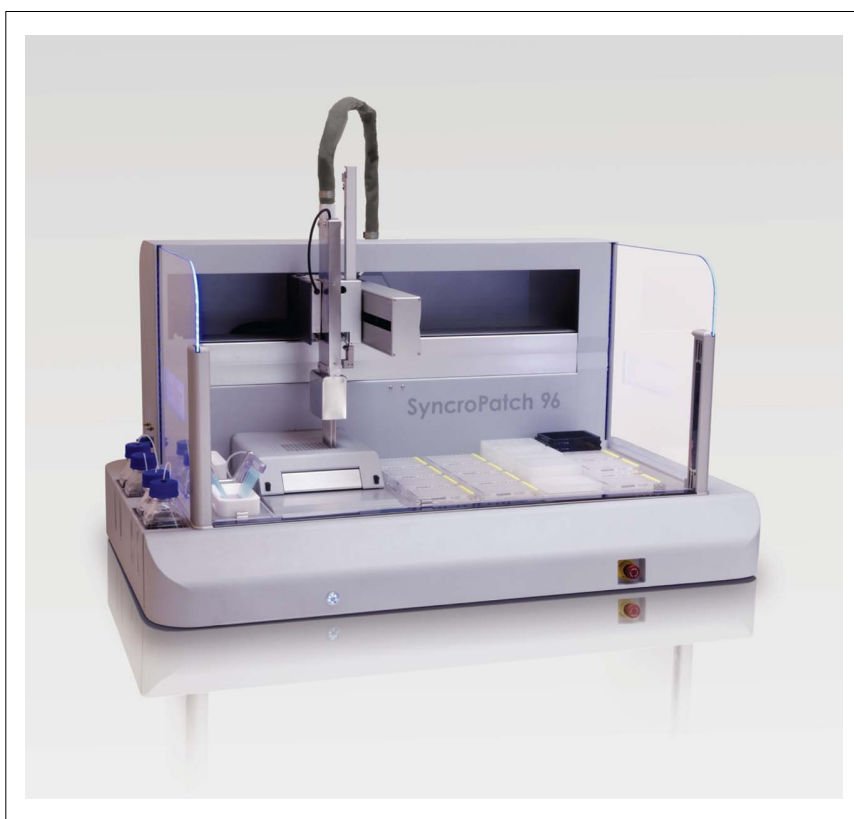

FIGURE 7 |The SyncroPatch 96 is an automated patch clamp device for parallel recordings and online analysis of up to $\mathbf{9 6}$ cells. All 96 cells are voltage clamped at any time. The pipette arm contains 16 channels, therefore 16 of the cells are served with solution in parallel. The device utilizes planar borosilicate-glass chips. The solution exchange for the individual cell is in the range of $100 \mathrm{~ms}$.

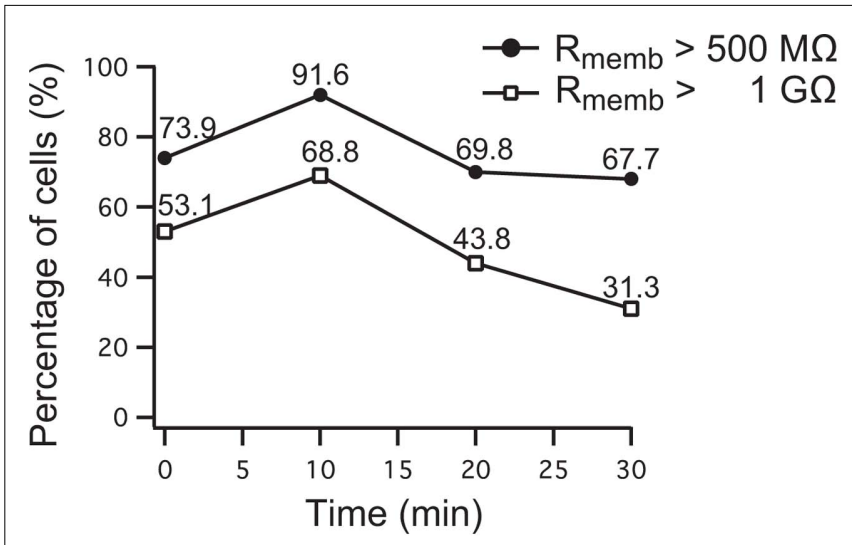

FIGURE 8 | Development of seal stability of $96 \mathrm{Na}_{\mathrm{v}} \mathbf{1 . 5}$ overexpressing HEK cells over time on the SyncroPatch 96. $69.8 \%$ of the cells had a stable membrane resistance of $>500 \mathrm{M} \Omega(783 \pm 29 \mathrm{M} \Omega)$ for $20 \mathrm{~min}, 67.7 \%$ of the cells were stable until the experiment was finished after $30 \mathrm{~min}$. $43.8 \%$ of cells having a membrane resistance of $>1 \mathrm{G} \Omega(1865 \pm 99 \mathrm{M} \Omega)$ were stable for $20 \mathrm{~min}, 31.3 \%$ of them still had a stable resistance after $30 \mathrm{~min}$. Note the increase of cell percentage developing a higher resistance within $10 \mathrm{~min}$ after reaching the whole cell configuration.

the heated solution was applied to the cell at a speed of $10 \mu \mathrm{l} / \mathrm{s}$. Outwardly rectifying currents started to activate at $38^{\circ} \mathrm{C}$ and increased in amplitude as temperature increased, up to $54^{\circ} \mathrm{C}$, in good agreement with the literature (Peier et al., 2002; Smith et al., 2002; Xu et al., 2002). 


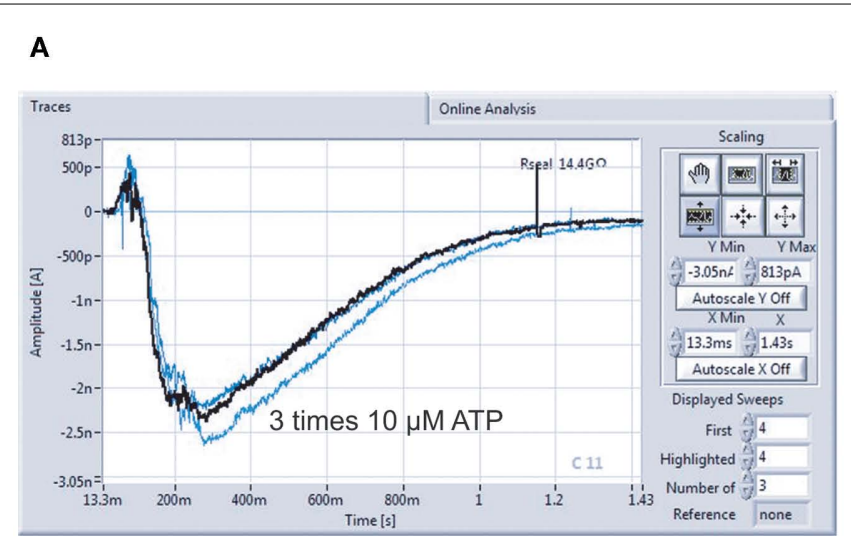

FIGURE 9 | Multiple compound additions can be performed, allowing the generation of full concentration response curves on individual cells. (A) $\mathrm{P} 2 \mathrm{X}_{2 / 3}$ receptors expressed in a $1321 \mathrm{~N} 1$ cell were repeatedly activated by $10 \mu \mathrm{M}$ ATP (three times activation with

\section{B}

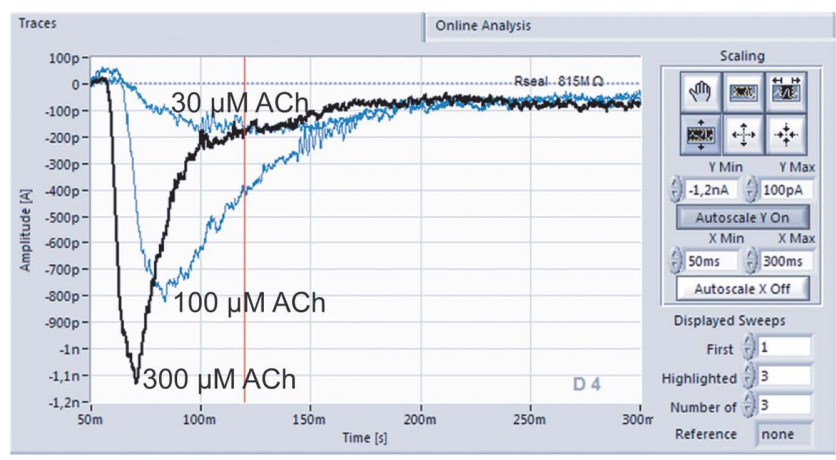

intermittent wash steps; data courtesy of Evotec AG). (B) Activation of nicotinic $\alpha 7$ receptors with 30,100, and $300 \mu \mathrm{M}$ Ach in one cell. Cells stably expressing human nAChRs were kindly provided by Galantos Pharma $\mathrm{GmbH}$.

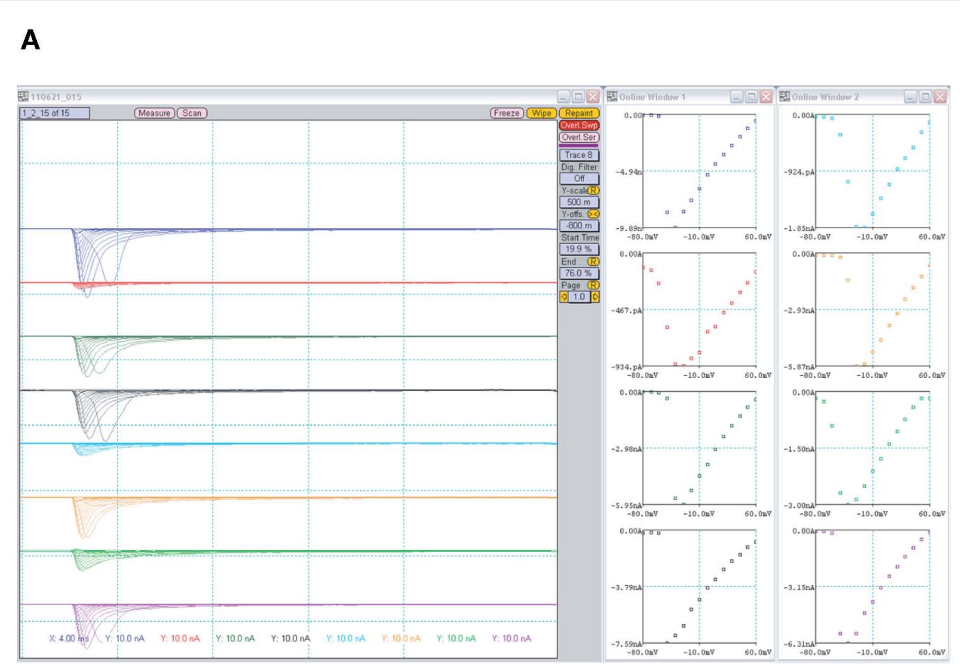

B
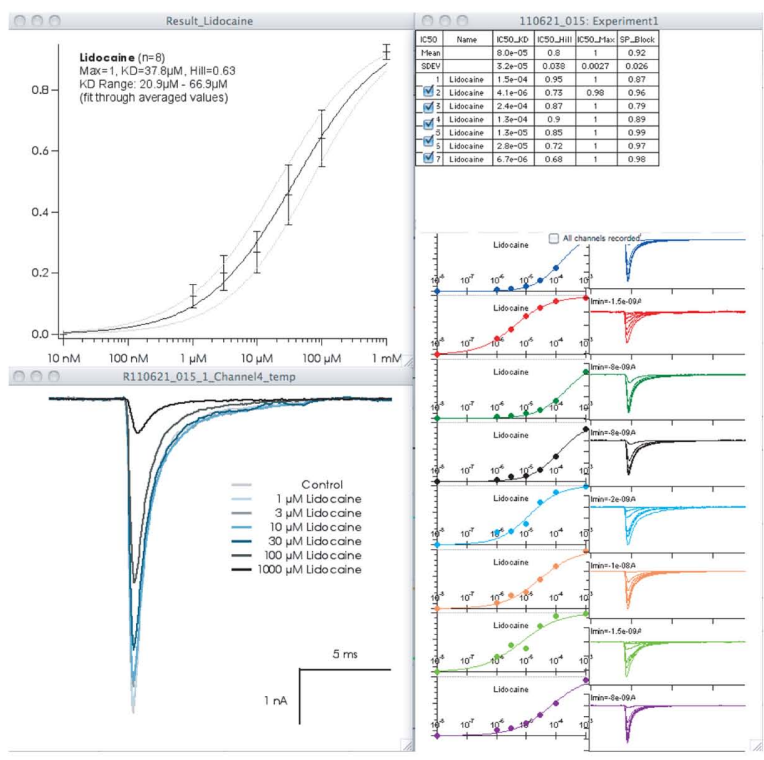

\section{는}

Oscilloscope window in PatchMaster showing raw data traces

\section{Online Analysis window in PatchMaster showing} current - voltage relations
ᄂ

Summary of calculated $\mathrm{IC}_{50} \mathrm{~S}$ (top graph) and exemplary raw data traces (lower graph) in Igor Pro
$\mathrm{IC}_{50}$ calculations (top table) and graphical depictions (below) of individual cells in Igor Pro
FIGURE 10 | (A) Graphical user interface for software used on a Patchliner system. PatchMaster raw data files from eight parallel recordings of $\mathrm{Na}_{\mathrm{v}} 1.5$ expressing HEK cells. A screenshot of the oscilloscope with current traces and online analysis windows with corresponding current-voltage relations are shown. Data are loaded into IGOR Pro (B) with aid of a macro. After a few mouse clicks, individual $I C_{50}$ values for a compound (here lidocaine) from each cell and the averaged data, including all relevant values and calculations, are displayed.

\section{PARALLEL CURRENT CLAMP MEASUREMENTS}

The Patchliner was used in combination with stem cell-derived cardiomyocytes, a standardized and pure cardiac myocyte model. This is a new opportunity because cardiac toxicity can now be evaluated in a cell type which better represents the real physiological environment compared with a cell line overexpressing a particular ion channel. Patch clamp measurements with cardiac myocytes are sophisticated experiments that were, until now, 
only possible using conventional patch clamp using freshly isolated cardiac myocytes from animals. Stem cell-derived cardiac myocytes are commercially available, a pure population and readyto-use resulting in a quicker cell preparation time and better reproducibility of the assay.

The Patchliner was used for pharmacological experiments in both voltage clamp and current clamp modes so that the effects of cardiotoxic compounds could be directly investigated on both ion currents and APs. The eight-channel system Patchliner and the one-channel system Port-a-Patch (Farre et al., 2007) are the currently only APC devices which allow for both voltage and current clamp recordings. We used mouse stem cell-derived Cor.At cardiomyocytes and human iPS cell-derived iCell cardiomyocytes. The cells showed expression of $\mathrm{Na}^{+}, \mathrm{Ca}^{2+}$, and $\mathrm{K}^{+}$channels in the voltage clamp mode after a minimum of 2 days of culturing (for Cor.At cells, see also Stoelzle et al., 2011). Cor.At cardiomyocytes which had been in culture for more than 4 days required a prolonged incubation with the digestion enzyme to obtain single cell suspensions. This in turn reduced the success rates to obtain gigaohm seals, hence we used cells that were in culture for 2-4 days. We did not see a difference between those cells with regards to channel expression or success rate.

After optimization of the harvesting methods, the Cor.At and iCell cardiomyocytes had a high success rate when used on the Patchliner, which resulted in long lasting recordings both in voltage clamp and current clamp modes (Figures 5 and 6). A typical pharmacological experiment in the voltage clamp mode using multiple concentrations of a compound (in this case TTX) and washout to check reversibility was performed with a Patchliner (Figures 5A-C and 6) and also with the Port-a-Patch (Figures 5E,F). In the current clamp mode, APs were elicited by a short depolarizing pulse ( $1 \mathrm{~ms}$ current injection to the threshold at which an AP was elicited). The shape was not only comparable to the shape of APs recorded with the one-cell-at-a-time system Port-a-Patch and a conventional patch clamp rig (Figure 5G), but also stable over a long period of time (Figure 5D), confirming that the cells are suitable for analyzing compound effects on APs. Therefore the generation of a full concentration response curve on an individual cell can be generated easily due to the stability of the measurements (Figure 5D; see also Stoelzle et al., 2011). Pharmacological experiments on APs have been extensively studied on Cor.At cells, including a study on frequency dependent inhibition of $\mathrm{Na}^{+}$channels (Stoelzle et al., 2011). Figure 6C shows APs generated using iCell cardiomyocytes using a short depolarizing pulse (as described above) and the expected shortening of the AP duration and a slowing of velocity of the upstroke by increasing concentrations of TTX. The $\mathrm{IC}_{50}$ achieved in the current clamp mode $\left[\mathrm{IC}_{50}=5.6 \mu \mathrm{M}(n=2)\right]$ agrees well with the $\mathrm{IC}_{50}$ from voltage clamp $[2.5 \pm 0.9 \mu \mathrm{M}(n=4)]$. Table 3 shows success rate and cell parameters for iCell cardiomyocytes $(n=69)$.

\section{HIGH-THROUGHPUT AUTOMATED PATCH CLAMP}

The SyncroPatch 96 (Figure 7) is a screening platform which generates high quality patch clamp data and provides accurate pharmacology because full dose response curves can be acquired from individual cells with giga-ohm seals. It is a well suited tool for secondary screening efforts and for safety testing either for dose
Table 1 | Success rate, cell parameters, and experiment duration for $n=35$ HEK cells stably expressing hERG.

\begin{tabular}{lllll}
\hline Success rate (\%) & $\boldsymbol{R}_{\text {memb }}(\mathbf{G} \boldsymbol{\Omega})$ & $\mathbf{C m}(\mathbf{p F})$ & $\mathbf{R s}(\mathbf{M} \boldsymbol{\Omega})$ & $\begin{array}{l}\text { Exp. duration } \\
(\mathbf{m i n})\end{array}$ \\
\hline 65 & $2.4 \pm 0.5$ & $7.9 \pm 1$ & $7.0 \pm 1$ & $19 \pm 2$ \\
\hline
\end{tabular}

Parameters of cells recorded at $R T$ and $35^{\circ} \mathrm{C}$ were pooled since no difference was observed between those conditions. Given errors are standard errors of the mean. Sixty-five percent of the cells had a membrane resistance of $2.4 \pm 0.5 \mathrm{G} \Omega$; the seals were stable over $19 \pm 2 \mathrm{~min}$.

Table 2 | Success rate, cell parameters, and experiment duration for $n=87$ HEK cells stably expressing TRPV3.

\begin{tabular}{lllll}
\hline Success rate (\%) & $\boldsymbol{R}_{\text {memb }}(\mathbf{M} \Omega)$ & $\mathbf{C m}(\mathbf{p F})$ & $\mathbf{R s}(\mathbf{M} \boldsymbol{\Omega})$ & $\begin{array}{l}\text { Exp. duration } \\
\text { (min) }\end{array}$ \\
\hline 81 & $934 \pm 191$ & $18 \pm 1$ & $6.2 \pm 0.4$ & $39 \pm 2$
\end{tabular}

Given errors are standard errors of the mean. Eighty-one percent of the cells had a membrane resistance of $934 \pm 191 \mathrm{M} \Omega$, the seals were stable over $39 \pm 2 \mathrm{~min}$.

Table 3 | Success rate, cell parameters, and experiment duration for $n=69$ iCell cardiomyocytes.

\begin{tabular}{lllll}
\hline Success rate (\%) & $\boldsymbol{R}_{\text {memb }}(\mathbf{G} \Omega)$ & $\mathbf{C m}(\mathbf{p F})$ & $\mathbf{R s}(\mathbf{M} \Omega)$ & $\begin{array}{l}\text { Exp. duration } \\
\text { (min) }\end{array}$ \\
\hline 46 & $1.4 \pm 0.3$ & $12.9 \pm 1$ & $6.0 \pm 0.6$ & $18.2 \pm 1$ \\
\hline
\end{tabular}

Given errors are standard errors of the mean. Forty-six percent of the cells had a membrane resistance of $1.4 \pm 0.3 \mathrm{G} \Omega$, the seals were stable over $18.2 \pm 1 \mathrm{~min}$.

Table 4 | In total, 64 of the 96 cells reached a seal resistance of around $1.8 \mathrm{G} \Omega$ within the first $10 \mathrm{~min}$ after reaching the whole cell mode, 21 cells reached a resistance of around $783 \mathrm{M} \Omega$.

\begin{tabular}{llll}
\hline $\begin{array}{l}\text { Number } \\
\text { of cells }\end{array}$ & $\begin{array}{l}\boldsymbol{R}_{\text {memb }} \\
(\mathbf{M} \boldsymbol{\Omega})\end{array}$ & $\begin{array}{l}\text { Number of cells stable } \\
\text { for } \mathbf{2 0} \mathbf{m i n}(\boldsymbol{\%})\end{array}$ & $\begin{array}{l}\text { Number of cells stable } \\
\text { for } \mathbf{3 0} \mathbf{~} \mathbf{i n}(\mathbf{\%})\end{array}$ \\
\hline 64 & $1865 \pm 99$ & 43.8 & 31.3 \\
21 & $783 \pm 29$ & 69.8 & 67.7 \\
11 & $152 \pm 48$ & n.a. & n.a.
\end{tabular}

The remaining cells had a resistance of around $152 \mathrm{M} \Omega .43 .8 \%$ of the cells having a giga-ohm seal remained their seal for $20 \mathrm{~min}, 31.3 \%$ had the giga-ohm seal still after $30 \mathrm{~min}$. $69.8 \%$ of the cells having around $783 \mathrm{M} \Omega$ as a seal resistance remained their seal for $20 \mathrm{~min}, 67.7 \%$ for $30 \mathrm{~min}$. $N=96$ cells, recorded on one NPC-96 patch clamp chip, given errors are standard errors of the mean.

response analysis or single-point screening. Table 4 shows success rates of representative experiments using $\mathrm{Na}_{\mathrm{v}} 1.5$ overexpressing HEK cells on one patch clamp chip (NPC-96 patch clamp chip for 96 cells being recorded in parallel). Furthermore, the stability of cells over time is listed as well. Figure $\mathbf{8}$ shows a corresponding graphical depiction of the development of the seal stability over time. 
Voltage clamp recordings are continuous during compound application and solution exchange time is in the order of $100 \mathrm{~ms}$. This allows for screening of compound action on ligand- and voltage-gated ion channels. An APC device with fast solution exchange is a prerequisite for studying fast desensitizing channels such as nicotinic acetylcholine receptor (nAChR). Enhancers of nAChRs, such as galantamine, may have therapeutic benefit for Alzheimer's disease (Samochocki et al., 2003). It is, therefore, essential to be able to search for $\mathrm{nAChR}$ agonists and enhancers at a higher throughput.

Figure 9A shows a typical screenshot with recordings of a ligand-gated ion channel, $\mathrm{P}_{2} \mathrm{X}_{2 / 3} . \mathrm{P}_{2} \mathrm{X}_{2 / 3}$ receptors in a $1321 \mathrm{~N} 1$ cell were repeatedly activated by $10 \mu \mathrm{M}$ ATP, demonstrating the reliability of repetitive drug applications. nAChR $\alpha 7$ expressing HEK cells were activated by increasing concentrations of ACh $(30,100,300 \mu \mathrm{M}$; Figure 9B). Given the importance of this channel as a potential therapeutic target for conditions such as Alzheimer's disease, schizophrenia, and Parkinson's disease (for review see Colquhoun et al., 2003; Albuquerque et al., 2009), it is critical that researchers have tools to study them reliably.

The disposable planar borosilicate-glass substrate used for seal formation ensures high quality data and long lasting seals when using the Patchliner and SyncroPatch 96. In general, with a success rate for completed experiments of $51.7 \pm 10 \%(n=567)$, the SyncroPatch 96 has a data throughput of approximately 5000 data point per day. With a Patchliner Octo, having a success rate of around $80 \%$, approximately 500 data points can be generated per day (Farre et al., 2009).

\section{DATA ANALYSIS}

Increasing the throughput in APC devices results in an increase in data generation and, thereby, necessitates the need for automated data analysis. Figure 10A shows a screenshot of one run on a Patchliner Octo, which records from eight cells at a time. Here, $\mathrm{Na}_{\mathrm{v}} 1.5$ stably expressing HEK cells were used (Millipore, USA). The raw data are saved as PatchMaster (.dat) files and an additional Microsoft office excel spreadsheet is generated, which can be easily loaded in IGOR Pro (WaveMetrics, USA). We developed a macro which is implemented in IGOR Pro that enables the upload, graphical display of raw data traces and $\mathrm{IC}_{50}$ calculation of individual cells or an average of all cells for each compound in summary (Figure 10B).

For the analysis of concentration response curves, the SyncroPatch 96 software provides an intuitive graphical user interface (Figure 11). The recording sites are color coded according to user defined success criteria (membrane resistance, access resistance, current amplitude etc.). The user can generate individual $\mathrm{IC}_{50}$ values or an average $\mathrm{IC}_{50}$ of the recorded cells. Current-voltage relationships, leak-subtraction, and time-dependence of recorded values can be displayed besides a repertory of other calculations.

\section{DISCUSSION AND OUTLOOK}

The APC devices used here for data recordings are equipped for studying ion channels in various areas of research, drug discovery, and safety screening. The data quality and reproducibility of pharmacological experiments is consistent between the automated systems and a manual patch clamp rig or semi-automated patch clamp system like the Port-a-Patch as shown for current clamp
A

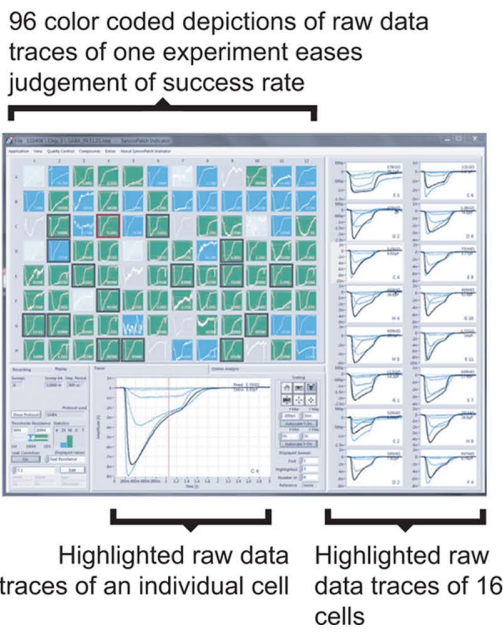

96 color coded depictions of the analysis of all recorded cells

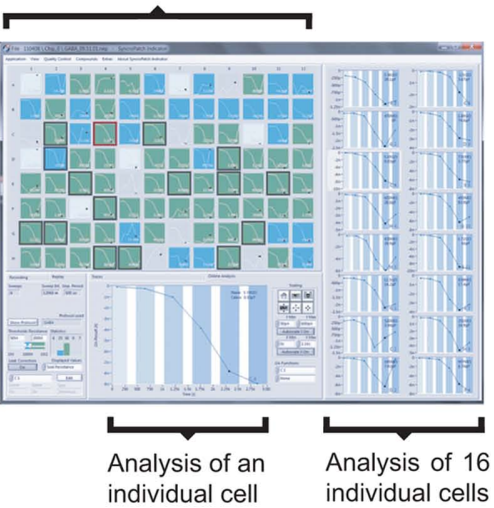

C

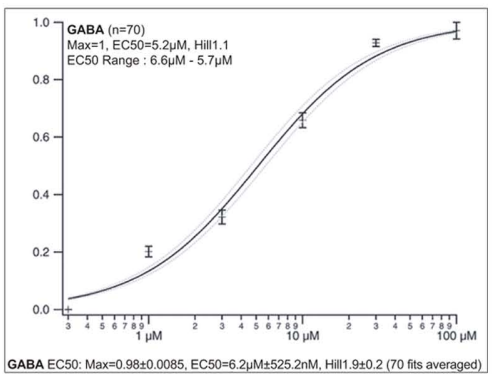

FIGURE 11 | Graphical user interface of the screening and data analysis software used on the SyncroPatch 96. (A) Screenshot of depiction of raw data of $\mathrm{GABA}_{\mathrm{A}}$ subunits $\alpha 1 \beta 2 \gamma 2$ expressing HEK cells as recorded on one NPC-96 patch clamp chip. Ninety-six small color coded pictures as seen in the upper left part display all 96 parallel recordings. Depending on the seal resistance, pictures are green $\left(R_{\text {memb }}>100 \mathrm{M} \Omega\right)$, blue $\left(R_{\text {memb }}=50-100 \mathrm{M} \Omega\right)$, light blue or gray $\left(R_{\text {memb }}<50 \mathrm{M} \Omega\right.$ or no cell capture). One highlighted experiment is displayed below, 16 other selected experiments are displayed on the right. Traces show currents of individual cells which were activated by six GABA concentrations $(0.3,1,3,10,30$, and $100 \mu \mathrm{M})$. Intermittent wash steps with control solution were performed. (B) Screenshot showing the same experiment as in (A), but displaying individual concentration response curves. For highlighted experiments (in lower part and right), note the different shades of blue overlaid on the curves, representing the six increasing concentrations of GABA. The white color represents the intermittent wash steps. (C) Averaged concentration response curve and related parameters of successful experiments (here 70 out of 96) of the same experiment. 
recordings from pluripotent stem cell-derived cardiomyocytes. The overall instrument performance, success rates, longevity of recordings, and compatibility with various cell lines and assay types are fundamental for effective screening work in electrophysiology departments. Effective screening in the broader sense also means cost effectiveness, which is, of course, an essential qualification. The combination of an in vitro cardiac cell model with higher throughput patch clamp screening technology opens up a new way for cardiotoxicity prediction in a physiologically relevant cell system. The ability to perform current clamp recordings and a temperature-regulated cell environment are unique features of the Patchliner, currently not available on other higher throughput APC systems. Furthermore, the temperature control feature of the Patchliner can be used to record ion currents and APs at physiological temperatures and to activate temperature-regulated receptors such as the TRP family of receptors to discover specific inhibitors with a reduced side-effect profile. The data shown on TRP channels prove not only the versatility of the liquid handling that is needed to repeatedly activate the cell by perfusing heated solution, but also the exactness of heating and precisely timed exposure of the cell to the heated solution.

The Patchliner is compatible with many different cell lines, showing little discrepancy between the cell lines used (data described in this paper and Bruggemann et al., 2006; Farre et al., $2007,2009)$. Interestingly, recordings of a variety of primary cells have also been described using the Patchliner (Milligan et al., 2009). Few, if any, other APC devices have been able to demonstrate such compatibility with primary cells.

\section{REFERENCES}

Albuquerque, E. X., Pereira, E. F., Alkondon, M., and Rogers, S. W. (2009). Mammalian nicotinic acetylcholine receptors: from structure to function. Physiol. Rev. 89, 73-120.

Ashcroft, F. M. (2000). Ion Channels and Disease: Channelopathies, London: Academic Press.

Balansa, W., Islam, R., Fontaine, F., Piggott, A. M., Zhang, H., Webb, T. I., Gilbert, D. F., Lynch, J. W., and Capon, R. J. (2010). Ircinialactams: subunit-selective glycine receptor modulators from Australian sponges of the family Irciniidae. Bioorg. Med. Chem. 18, 2912-2919.

Bruggemann, A., Farre, C., Haarmann, C., Haythornthwaite, A., Kreir, M., Stoelzle, S., George, M., and Fertig, N. (2008). Planar patch clamp: advances in electrophysiology. Methods Mol. Biol. 491, 165-176.

Bruggemann, A., Stoelzle, S., George, M., Behrends, J. C., and Fertig, N. (2006). Microchip technology for automated and parallel patch-clamp recording. Small 2, 840-846.

Chung, M. K., Lee, H., Mizuno, A., Suzuki, M., and Caterina, M.

In both academic and pharmaceutical laboratories it is of advantage to be able to record ion channels in a more physiologically relevant environment, e.g., primary cell cultures, for drug discovery, biophysical and physiological analysis, and safety pharmacology using an APC system.

Fast external exchange, minimal compound exposure, and continuous current recording make the Patchliner and SyncroPatch 96 suited to ligand-gated ion channel measurements. Fast desensitizing receptors such as the nicotinic $\alpha 7$ receptor can be reliably recorded when taking advantage of the possibility to minimize the exposure time of the cell to the compound. The applied compound solution, e.g., containing the ligand can be replaced by a control solution after $200 \mathrm{~ms}$. Volumes of the ligand containing or control solution and speed of application are set by the user to control speed of exchange and ligand exposure time. Settings can be adapted according to the receptor of interest to optimize reproducibility of current responses.

Providers of APC devices constantly strive to improve and extend the application range of these devices and features. As described in this manuscript, recordings in the current clamp mode and at physiological temperature are relevant features and will be of good use in the future in both academic and pharmaceutical research.

\section{ACKNOWLEDGMENTS}

We thank Davide Pau, Scottish Biomedical, UK for performing AP recordings on a conventional patch clamp rig and for letting us use his data.

electrophysiology for secondary screening and safety pharmacology. Comb. Chem. High Throughput Screen. 12, 24-37.

Farre, C., Stoelzle, S., Haarmann, C. George, M., Bruggemann, A., and Fertig, N. (2007). Automated ion channel screening: patch clamping made easy. Expert Opin. Ther. Targets 11, 557-565.

Gudermann, T., and Flockerzi, V. (2005). TRP channels as new pharmacological targets. Naunyn Schmiedebergs Arch. Pharmacol. 371, 241-244.

Guo, J., Zhan, S., Lees-Miller, J. P., Teng, G., and Duff, H. J. (2005). Exaggerated block of hERG (KCNH2) and prolongation of action potential duration by erythromycin at temperatures between 37 degrees $\mathrm{C}$ and 42 degrees C. Heart Rhythm 2, 860-866.

Hille, B. (1992). Ionic Channels of Excitable Membranes. Sunderland, MA: Sinauer Associates.

Hu, H., Grandl, J., Bandell, M., Petrus, M., and Patapoutian, A. (2009). Two amino acid residues determine 2-APB sensitivity of the ion channels TRPV3 and TRPV4. Proc. Natl. Acad. Sci. U.S.A. 106, 1626-1631.
Kolossov, E., Bostani, T., Roell, W., Breitbach, M., Pillekamp, F., Nygren, J. M., Sasse, P., Rubenchik, O., Fries, J. W., Wenzel, D., Geisen, C., Xia, Y., Lu, Z., Duan, Y., Kettenhofen, R., Jovinge, S., Bloch, W., Bohlen, H., Welz, A., Hescheler, J., Jacobsen, S. E., and Fleischmann, B. K. (2006). Engraftment of engineered ES cellderived cardiomyocytes but not BM cells restores contractile function to the infarcted myocardium. J. Exp. Med. 203, 2315-2327.

Li, J., Sukumar, P., Milligan, C. J., Kumar, B., Ma, Z. Y., Munsch, C. M., Jiang, L. H., Porter, K. E., and Beech, D. J. (2008). Interactions, functions, and independence of plasma membrane STIM1 and TRPC1 in vascular smooth muscle cells. Circ. Res. 103, e97-e104.

Milligan, C. J., Li, J., Sukumar, P., Majeed, Y., Dallas, M. L., English, A., Emery, P., Porter, K. E., Smith, A. M., Mcfadzean, I., Beccano-Kelly, D., Bahnasi, Y., Cheong, A., Naylor, J., Zeng, F., Liu, X., Gamper, N., Jiang, L. H., Pearson, H. A., Peers, C., Robertson, B., and Beech, D. J. (2009). Robotic multiwell planar patch-clamp for native and primary mammalian cells. Nat. Protoc. 4, 244-255. 
Stoelzle et al.

State-of-the-art automated patch clamp

Neher, E., and Sakmann, B. (1976). Single-channel currents recorded from membrane of denervated frog muscle fibres. Nature 260, 799-802.

Peier, A. M., Reeve, A. J., Andersson, D. A., Moqrich, A., Earley, T. J., Hergarden, A. C., Story, G. M., Colley, S., Hogenesch, J. B., Mcintyre, P., Bevan, S., and Patapoutian, A. (2002). A heat-sensitive TRP channel expressed in keratinocytes. Science 296, 2046-2049.

Samochocki, M., Höffle, A., Fehrenbacher, A., Jostock, R., Ludwig, J., Christner, C., Radina, M., Zerlin, M., Ullmer, C., Pereira, E. F. R., Lübbert, H., Albuquerque, E. X., and Maelicke, A. (2003). Galantamine is an allosterically potentiating ligand of neuronal nicotinic but not of muscarinic acetylcholine receptors. J. Pharmacol. Exp. Ther. 305, 1024-1036.

Smith, G. D., Gunthorpe, M. J., Kelsell, R. E., Hayes, P. D., Reilly, P., Facer, P., Wright, J. E., Jerman, J. C., Walhin, J. P., Ooi, L., Egerton, J., Charles, K. J., Smart, D., Randall, A. D., Anand, P., and Davis, J. B. (2002). TRPV3 is a temperature-sensitive vanilloid receptor-like protein. Nature 418, 186-190.

Stanat, S. J., Carlton, C. G., Crumb, W. J. Jr., Agrawal, K. C., and Clarkson, C. W. (2003). Characterization of the inhibitory effects of erythromycin and clarithromycin on the HERG potassium channel. Mol. Cell. Biochem. 254, 1-7.

Stoelzle, S., Haythornthwaite, A., Kettenhofen, R., Kolossov, E., Bohlen, H., George, M., Bruggemann, A., and Fertig, N. (2011). Automated patch clamp on mESC-derived cardiomyocytes for cardiotoxicity prediction. J. Biomol. Screen.

Xu, H., Ramsey, I. S., Kotecha, S. A., Moran, M. M., Chong, J. A., Lawson, D., Ge, P., Lilly, J., Silos-Santiago, I., Xie, Y., Distefano, P. S., Curtis, R., and Clapham, D. E. (2002). TRPV3 is a calcium-permeable temperaturesensitive cation channel. Nature 418, 181-186.

Conflict of Interest Statement: The authors declare that the research was conducted in the absence of any commercial or financial relationships that could be construed as a potential conflict of interest.

Received: 01 August 2011; accepted: 07 November 2011; published online: 24 November 2011.
Citation: Stoelzle S, Obergrussberger A, Brüggemann A, Haarmann C, George $M$, Kettenhofen $R$ and Fertig $N$ (2011) State-of-the-art automated patch clamp devices: heat activation, action potentials, and high throughput in ion channel screening. Front. Pharmacol. 2:76. doi: 10.3389/fphar.2011.00076

This article was submitted to Frontiers in Pharmacology of Ion Channels and Channelopathies, a specialty of Frontiers in Pharmacology.

Copyright (c) 2011 Stoelzle, Obergrussberger, Brüggemann, Haarmann, George, Kettenhofen and Fertig. This is an open-access article subject to a nonexclusive license between the authors and Frontiers Media SA, which permits use, distribution and reproduction in other forums, provided the original authors and source are credited and other Frontiers conditions are complied with.

www.frontiersin.org

November 2011 | Volume 2 | Article 76 | 11 